\title{
A enunciação da imagem feminina nas redes sociais: uma investigação à luz da teoria dialógica da linguagem
}

\author{
The enunciation of the female image in social networks: an \\ investigation based on the dialogic theory of language
}

\author{
Antonio Flavio Ferreira de Oliveira \\ flavioccaa@hotmail.com \\ Universidade Federal da Paraíba \\ Tarciana Karla Rodrigues Pereira* \\ tarciana-karlla@hotmail.com \\ Universidade Estadual da Paraíba
}

\begin{abstract}
RESUMO: Este trabalho investiga sobre o processo de enunciação da mulher nas redes sociais. Desse modo, objetiva refletir como a imagem feminina tem sido discursivizada em blogs, websites e em grupos do Facebook. A proposta de análise foi fundamentada pelos pressupostos teórico-metodológicos da Teoria Dialógica da Linguagem. Os aspectos metodológicos estabelecem uma pesquisa qualitativa de cunho interpretativista. O corpus foi constituído por quatro enunciados referentes à discursivização da mulher em blogs, websites e grupos do Facebook. Como resultado, foi constatado que a enunciação da imagem feminina constrói sentidos a partir do cruzamento das enunciações de diversas vozes sociais e que essas vozes sociais constituem o sujeito mulher como um ser social em devir.
\end{abstract}

PALAVRAS-CHAVE: Teoria dialógica da linguagem. Enunciação. Imagem feminina. Redes sociais.

\begin{abstract}
This work investigates the process of enunciating women in social networks. Thus, it aims to reflect on how the female image has been enunciated in blogs, websites, and Facebook groups. The analysis was based on the methodological and theoretical approach of the Dialogic Theory of Language. The methodological aspects determine a qualitative-interpretative research. The corpus was constituted of four (04) utterances related to the discursivization of women in blogs, websites and Facebook groups. The result established that the enunciation of female images produce senses as enunciations of different social voices are crossed and that these voices constitute the woman as a social subject in becoming.
\end{abstract}

KEYWORDS: Dialogical theory of language. Enunciation. Female image. Digital social networks.

\footnotetext{
Trabalho de pesquisa realizado sob a orientação do Prof. Antonio Flavio Ferreira de Oliveira, mestre e doutorando em Linguística pela Universidade Federal da Paraíba (UFPB)
} 


\section{Introdução}

Nesta pesquisa, queremos apresentar uma discussão referente ao modo como a imagem feminina é enunciada nas redes sociais. Dessa maneira, usaremos os postulados da Teoria Dialógica da Linguagem (doravante TDL) para confrontarmos com os fatos discursivos e para podermos compreender como os sentidos referentes à constituição da imagem do sujeito mulher podem ser estabelecidos no processo de discursivização nos gêneros digitais e midiáticos.

$\mathrm{Na}$ discursivização da imagem feminina nas redes sociais, encontramos fatores enunciativos que podem constituir o sujeito mulher como um elemento social construído a partir da discursivização de imagens que são carregadas de valores sociais, históricos e ideológicos. Para isso, são levadas em conta as condições sociais de produção do dizer, ou seja, todos os elementos exteriores à linguagem, os elementos que configuram os aspectos subentendidos e presumidos dos discursos sociais.

Tendo em vista que os gestos imagéticos produzem sentidos mediante a essas condições discursivas, o presente trabalho objetiva investigar como é discursivizada a imagem feminina nas redes sociais, principalmente em enunciados imagético-verbais do Facebook e de blogs.

Para atingirmos esse objetivo, levantamos as seguintes perguntas exploratórias: (1) qual a relação de sentido(s) no deslocamento da imagem feminina dispersada pelo tempo? e (2) que vozes sociais são estabelecidas na enunciação das imagens? Essas perguntas serviram de base para constituirmos a problemática de nossa pesquisa e, desse modo, a pergunta norteadora se configura em saber: que sentidos são estabelecidos na discursivização da imagem feminina nas redes sociais?

De modo particular, neste trabalho, discutimos sobre as relações de sentido(s) que ocorrem por meio do deslocamento da imagem feminina transpassada no tempo e sobre as situações e condições enunciativas pelas quais o sujeito mulher se constitui através dos elementos temporais e espaciais. Visamos realizar um estudo verticalizado sobre como o sujeito se constitui como produto das interações sociais, sujeito esse constituído de valores históricos, ideológicos e culturais. 
Os procedimentos metodológicos que dão suporte a esta pesquisa estão fundamentados em uma pesquisa de cunho qualitativo-interpretativa. Sendo assim, o corpus foi composto por quatro imagens de páginas da Internet, principalmente em redes sociais relacionadas a blogs, a websites e ao Facebook. As imagens foram coletadas no ano de 2015 e se encontram no Blog Macho das Cavernas, no Blog Jornal Pequeno, no site http://cintiacosta.com/ e em um grupo do Facebook chamado Feministas Revolucionárias. As imagens estão relacionadas aos temas sociais constituídos de sentidos moventes dos papéis sociais da mulher no decorrer dos tempos.

Os critérios para a escolha do corpus se deram devido ao fato de a discursivização da imagem feminina poder expressar deslocamentos de diversos sentidos nas redes sociais. Para analisar as imagens, fizemos a leitura de conceitos e categorias instaurados pelos estudos do Círculo bakhtiniano e os contrastamos com os fatos dos enunciados.

Nas análises, procuramos investigar os sentidos estabelecidos pelas diversas discursivizações da imagem feminina nos gêneros digitais, bem como essas imagens podem gerar novas construções relativas de verdade, levando-se em conta todo o processo interacional onde está situado o sujeito mulher.

O estudo está organizado em duas seções: (1) uma fundamentação teórica, na qual estão estabelecidos alguns conceitos e categorias relevantes da TDL , e (2) a análise dos fatos discursivos a partir de quatro (04) enunciados referentes à enunciação da imagem da mulher.

\section{Teoria dialógica da linguagem: conceitos relevantes ${ }^{1}$}

Com base na TDL, deu-se início a uma vertente de estudos provenientes dos processos de interação que envolve a linguagem verbal e os aspectos históricosociais, questões essas que foram debatidas e postuladas por meio do Círculo bakhtiniano, recortes epistemológico-metodológicos relacionados à linguagem como um ponto de vista social, interacional e ideológico.

A linguagem faz parte de todos os horizontes (ideológicos, histórico, cultural, etc.) dos seres humanos e a linguística, por si só, não consegue compreendê-la em

\footnotetext{
${ }^{1}$ É pertinente destacar que os conceitos os quais chamamos relevantes estão relacionados ao recorte da pesquisa.
} 
sua totalidade. Isso se deve ao aspecto dinâmico que a língua proporciona ao ser humano; o homem (como sujeito do discurso) se utiliza da língua(gem) nas mais variadas relações sociais; logo, esse sujeito é o principal elemento de toda mudança que ocorre da concepção de língua que separa a linguística dos fatos da vida social.

O Círculo bakhtiniano estabeleceu os fundamentos teórico-metodológicos para o estudo da língua/linguagem, que visavam a uma ruptura com a noção de acabamento e estabilidade, oriunda do interior linguístico. Esses posicionamentos de ordem epistemológica partiram da crítica ao Círculo linguístico de Saussure, que constituiu a língua como parte de um sistema convencional e acabado.

A noção de língua advinda da gramática e do dicionário constitui características relacionadas ao conceito de convenção social presente no estruturalismo saussureano. É a partir do estabelecimento do processo interacional, pelo Círculo bakhtiniano, que o estudo da língua(gem) toma outro sentido, ou seja, passa a existir a noção de atos de linguagem constituídos da relação entre o sujeito social, a situação, os participantes e os elementos relacionados aos horizontes temporal e espacial.

Segundo Saussure (2012), a noção de língua está relacionada à parte coletiva e social que constitui a linguagem. Confira a seguinte citação:

Para nós, ela não se confunde com a linguagem; é somente uma parte determinada, essencial dela, indubitavelmente. É, ao mesmo tempo, um produto social da faculdade de linguagem e um conjunto de convenções necessárias, adotadas pelo corpo social para permitir o exercício dessa faculdade nos indivíduos (SAUSSURE, 2012, p. 41).

A partir dessa citação de Saussure (2012), podemos entender que a visão de língua estabelecida pelo autor difere dos posicionamentos do Círculo bakhtiniano, haja vista a língua ser entendida como uma parte constituída da linguagem e ser o elemento mais importante dessa constituição. Para o Círculo bakhtiniano, a fala, a enunciação, constitui-se o elemento de elevada importância, pois é por meio dela que podem ser compreendidos os valores individuais, constituídos socialmente. Através da enunciação, podemos compreender a função do sujeito como enunciador e o seu estilo particular de avaliar e preencher as palavras com os valores sociais. Nesse caso, língua passa a ser compreendia como uma materialidade semiótica que 
serve para compor a parte de significação do enunciado, e, nesses elementos semióticos, são colocados os sentidos construídos historicamente.

Se, por um lado, para o Círculo bakhtiniano, a língua é preconizada como um produto das necessidades humana, por outro, para Saussure, a língua é entendida como "um todo por si e um princípio de classificação" (SAUSSURE, 2012, p.41); ou seja, ela faz parte de um sistema que lhe é adquirido sem necessidades interacionais entre os seres pertencentes a uma dada esfera social.

O Círculo bakhtiniano estabelece que a língua deve ser caracterizada pelos seus aspectos reais e naturais, diferentemente de Saussure que a compreende como um "objeto abstrato" (BAKHTIN/VOLOCHÍNOV, 2014, p.14), um sistema único, desatento às suas manifestações sociais e individuais. Para que possamos compreender o sentido e o funcionamento da linguagem, é necessário levar em consideração os aspectos sociais que constituem o ser humano; é preciso compreender o outro ${ }^{2}$ através das diferentes formas de interação, como também nos seus modos distintos de manifestações sociais.

O Círculo bakhtiniano discorda da noção (estabelecida por Saussure) de que a língua é um sistema sólido e abstrato. De outra maneira, compreende-a como a expressão de fatos sociais materializados semioticamente e em movimento, em estado de inacabamento, sofrendo alterações e reconstruções. Nesse sentido, a fala (enunciação), para Bakhtin, constitui a força motriz dessas transformações; é aquela que instaura nas relações interacionais dos indivíduos o estilo (a entoação e as vozes sociais constituintes do sujeito); a fala está totalmente encadeada às relações comunicativas que, por sua vez, estão entrelaçadas a essas estruturas sociais. Costa (2010), comentando os estudos de Saussure, afirma que:

A língua é um sistema supra-individual utilizado como meio de comunicação entre os membros de uma comunidade. O entendimento Saussureano é o de que a língua corresponde à parte essencial da linguagem e constitui um tesouro - um sistema gramatical - depositado virtualmente nos cérebros de um conjunto de indivíduos pertencentes a uma comunidade linguística (COSTA, 2010, p. 116).

Saussure (2012) leva em consideração a língua como um objeto abstrato; dessa forma, ele não prioriza o teor de historicidade, mas apenas as formas

\footnotetext{
${ }^{2} \mathrm{O}$ outro é um elemento constituído da enunciação e é através dele que os sentidos são propriamente construídos.
} 
abstratas. Diferentemente, o Círculo bakhtiniano estuda o exercício da linguagem, tendo como ponto de vista a relação interacional entre os indivíduos. Para explicar o funcionamento da linguagem humana, o Círculo bakhtiniano toma, como ponto de partida, o objeto real, vivo e essencial (os aspectos exteriores à língua).

Segundo Bakhtin/Volochínov (2014, p. 96),

[o] locutor serve-se da língua para suas necessidades enunciativas concretas (para o locutor, a construção da língua está orientada no sentindo da enunciação da fala). Trata-se, para ele de utilizar as formas normativas (admitamos, por enquanto, a legitimidade destas) num dado contexto concreto. Para ele, o centro de gravidade da língua não reside na conformidade à norma da forma utilizada, mas na nova significação que essa forma adquire no contexto.

No aspecto concreto da utilização da língua, o falante não usa a palavra apenas como uma definição abstrata contida em um dicionário, mas a partir dos sentidos estabelecidos em um contexto particular. Assim, "a palavra está sempre carregada de um conteúdo ou de um sentindo ideológico ou vivencial" (BAKHTIN/VOLOCHÍNOV, 2014, p. 99).

A partir da crítica feita a Saussure, compreendemos que a língua, segundo Bakhtin/Volochínov (2014), é considerada como o resultado de toda interação humana; desse modo, a língua só produz sentidos quando está inserida no contexto das relações interacionais entre os sujeitos.

Segundo Bakhtin/Volochínov (2014), é através da enunciação que se inicia o estudo da interação verbal. "A enunciação é o produto da interação de dois indivíduos socialmente organizados e, mesmo que não haja um interlocutor real, este pode ser substituído pelo representante médio do grupo social ao qual pertence o locutor" (BAKHTIN/VOLOCHÍNOV, 2014, p. 116).

A enunciação não pode existir fora da realidade vivida, pois o homem faz parte do ato da fala no qual, dentro do seu corpo social, está inserido todo conteúdo ideológico - como o da ciência, da arte, dentre outros. Toda construção discursiva toma como orientação o outro, um (inter)locutor (fisicamente presente ou não na enunciação) que, por sua vez, orienta toda a enunciação. A palavra, segundo Bakhtin/Volochínov (2014), é o resultado da interação que acontece entre o locutor e o interlocutor, sujeitos que fazem parte da mesma comunidade linguística.

Com a ideia das esferas sociais, foram instaurados os pressupostos para os estudos dos gêneros do discurso. Para Bakhtin (2011), os gêneros do discurso não 
podem ser compreendidos sem tomar como referência o aspecto sócio-histórico da enunciação. É nas esferas sociais que os sujeitos exprimem os seus pontos de vista $e$, de forma particular, enunciam a partir das exigências comunicativas das esferas e das necessidades individuais. Em cada esfera existem os elementos necessários para que à língua sejam manifestados os fatos sociais de comum acordo aos sujeitos envolvidos no processo de interação, bem como o estilo individual que estabelece o emprego das materialidades semióticas da língua.

De maneira mais específica, Bakhtin (2011, p. 162) afirma serem os gêneros do discurso "tipos relativamente estáveis de enunciados". Desse modo, a noção de relatividade está relacionada aos possíveis deslocamentos da construção de sentidos dos enunciados nos diversos processos de interação nas esferas sociais.

No que diz respeito à estabilidade que configura os tipos de enunciados, podemos destacar que, na natureza de cada esfera, existe uma força motriz relacionada à constituição dessa esfera e sua relação com a exigência do processo de comunicação entre os sujeitos. Assim, podemos afirmar que é a relação entre relatividade e estabilidade que permite o deslocamento de sentidos na construção dos enunciados e a permanência do enunciado quanto à sua estrutura típica, ou seja, quanto à fixação da composição de cada enunciado configurado pelos elementos do estilo que envolvem a esfera, o sujeito e a língua.

Todo enunciado, seja ele oral ou escrito, primário ou secundário, faz parte de uma esfera da comunicação discursiva. Em toda esfera comunicativa existe a particularidade enunciativa e o estilo próprio de comunicação. Por isso, em cada esfera social existem determinados gêneros discursivos que são caracterizados a partir dos elementos que constituem o campo da criação ideológica, o projeto discursivo do sujeito, o estilo do sujeito, bem como os temas sociais pertinentes a enunciação. De acordo com Volochínov, (2013a, p.159; grifos do autor),

[e]ssa enunciação, enquanto unidade da comunicação verbal, enquanto unidade significante, elabora e assumme uma forma fixa precisamente no processo constituído por uma interação verbal particular, gerada num tipo particular de intercâmbio comunicativo social. Cada tipo de intercâmbio comunicativo referido anteriormente organiza, constrói e completa, à sua maneira, a forma gramatical e estilística da enunciação, sua estrutura tipo, que chamaremos a partir daqui gênero. 
Podemos compreender, a partir da citação, que os enunciados constituintes de sentidos e significações ${ }^{3}$ fazem parte de toda relação comunicativa social. Volochínov (2013a) estabelece os tipos de relações sociais nas quais são elaborados os diferentes modos de enunciados. São elas:

1. o intercâmbio comunicativo ligado à produção - nas fábricas, nas indústrias, na agricultura, etc.; 2. o intercâmbio comunicativo dos negócios - nos escritórios, nas organizações sociais, etc. 3. o intercâmbio comunicativo da vida cotidiana - encontros e conversas pela rua, a [conversação] permanente numa mesa social, na própria casa, etc.; 4. o intercâmbio comunicativo social no sentido próprio do termo - propagandístico, escolar, científico, filosófico, em todas as suas variações (VOLOCHÍNOV, 2013a, p.159; grifos do autor).

As esferas da atividade social são os lugares de onde emanam as relações sociais dos sujeitos. De maneira particular, nessas esferas acontecem as enunciações referentes às necessidades comunicativas do indivíduo. Dessas necessidades, são estabelecidos a situação discursiva e o seu auditório. De acordo com Volochínov (2013a, p.159; grifos do autor) a situação é "a efetiva realização na vida real de uma das formas, de uma das variedades, do intercâmbio comunicativo social". Já o auditório é a "presença dos participantes da situação" (VOLOCHÍNOV, 2013a, p. 159; grifos do autor).

Segundo Volochínov (2013a), as situações podem expressar diferentes atos de comunicação, como, por exemplo, uma exclamação, uma ordem e um pedido. "Toda situação inscrita duravelmente nos costumes possui um auditório organizado de uma certa maneira e consequentemente um certo repertório de pequenas fórmulas [gêneros] correntes" (BAKHTIN/VOLOCHÍNOV, 2014, p. 130).

Para Volochínov (2013a, p. 170):

Cada enunciação [enunciado], além dessa orientação social, contém um significado, um conteúdo. Privada desse conteúdo, a enunciação [o enunciado] torna-se um encadeamento de sons sem sentido e perde seu caráter de interação verbal.

O enunciado não é apenas a estrutura material do seu campo social; nele são depositados sentidos. Assim, se não levarmos em consideração o outro, nada

\footnotetext{
${ }^{3}$ Os sentidos estão relacionados aos fatores histórico-sociais constitutivos da linguagem. Já a significação está relacionada às unidades abstratas da língua.
} 
poderá compreender-se como enunciado; para cada enunciado vivo e real, consistem sentidos que Ihe são próprios. Para o Círculo bakhtiniano, a entoação, o modo particular como os sujeitos enunciam, é estabelecida pela situação e pelo auditório. A entoação dá sentindo ao enunciado, ela configura um aspecto relevante no uso das palavras nas relações sociais. É determinada pelo locutor e o seu ouvinte. A entoação é a peça chave da "expressão sonora da valoração social" (VOLOCHÍNOV, 2013a, p.175; grifos do autor).

Assim, para compreendermos o sentido da entoação, atentaremos para o "contexto extraverbal" (VOLOCHÍNOV, 2013b, p. 78; grifos do autor), pois a palavra, por si só, não é plena de sentido; o que a preenche de sentido é a sua esfera de comunicação, como também a interação, a constituição dos sujeitos, o horizonte espaço-temporal, etc.

Oliveira (2015, p. 37) afirma que:

A entoação avaliativa é compreendida como um fenômeno enunciativo-discursivo o qual estabelece que os sentidos são constituídos não pela materialidade semiótica, como por exemplo, a significação semântica abstrata da palavra, mas pela carga de valores sociais que é dada à palavra através de diversos tons sociais.

Para que o ouvinte possa compreender esse enunciado, é necessária a compreensão do contexto extraverbal, que consiste em três fatores: "um horizonte espacial compartilhado" dos interlocutores; "o conhecimento e a compreensão comum da situação"; e "a valoração compartilhada" pelos interlocutores (VOLOCHÍNOV, 2013b, p.78; grifos do autor). Para que seja realizada a compreensão desses fatores, podemos observar que o horizonte espacial é toda esfera ideológica onde se produzem os enunciados, é todo o ambiente onde são desenvolvidos esses enunciados.

O conhecimento e a compreensão dos enunciados se constituem a partir dos interlocutores; eles os compartilham, e a avaliação comum consiste no conhecimento comum do enunciado pelos sujeitos da interação.

A entoação preenche a palavra a partir de um determinado contexto. Através dela, a palavra deixa de ser vazia e passa a ser um enunciado. É através da 
entoação que a palavra é ligada à vida. No momento em que o falante se põe à frente do interlocutor, a entoação passa a ser constituída através de sentidos.

Segundo Bakhtin (2011), o enunciado se opõe à oração. Esta constitui uma unidade da língua e aquele uma unidade concreta da comunicação. O enunciado, portanto, não se estabelece através de normas linguísticas. Do contrário, vai além das formas gramáticas; nele é constituída a autoria (a função do sujeito como enunciador). Se, por um lado, o enunciado constitui unidade real da comunicação, por outro, a oração faz parte de uma unidade significativa da língua; a oração é marcada pela forma gramatical, sendo o enunciado marcado pela dinamicidade dos sujeitos e seus interlocutores.

O enunciado possui particularidades que o caracterizam como uma unidade concreta da comunicação. Desse exposto, podemos conceber elementos constitutivos da noção de dialogismo, que se fundem e se realizam mediante a interação verbal. Segundo Bakhtin (2011), os fatores contribuintes para a configuração do enunciado concreto estabelecem a relação do enunciado com o enunciador e todos os elementos constitutivos da comunicação e a alternância entre os sujeitos instituem o princípio da posição entre o eu/outro.

Para Bakhtin (2011), a alteração que ocorre entre os sujeitos da comunicação se dá a partir da réplica, sendo ela caracterizada como a unidade do enunciado da comunicação verbal entre os interlocutores. Segundo Bakhtin (2011), a réplica é uma posição, meramente, definida em que o enunciador se ocupa dentro de uma esfera da comunicação verbal, essas réplicas são também caracterizadas como atitudes responsivas. $\mathrm{O}$ sujeito, ao assumir uma posição social, manifesta sua visão de mundo e estilo, logo, cria posições e barreiras para tais réplicas, sendo ela feita em diferentes tons, seja de confirmação, de recusa, etc. "Cada réplica, por mais breve e fragmentária que seja, possui uma conclusibilidade específica ao exprimir certa posição do falante que suscita resposta, em relação à qual se pode assumir uma posição responsiva" (BAKHTIN, 2011, p. 275).

Quando o locutor dirige a palavra ao seu interlocutor, ele (o locutor) espera uma atitude ativa e responsiva. Essa resposta é o resultado da ação ativa do interlocutor, que compreende a enunciação do locutor e assume a sua posição responsiva e ativa. Veja a seguinte citação: 
[O] ouvinte, ao perceber e compreender o significado (linguístico) do discurso, ocupa simultaneamente em relação a ele uma ativa posição responsiva: concorda ou discorda dele (total ou parcialmente), completa-o, aplica-o, prepara-se para usá-lo, etc. (BAKHTIN, 2011, p. 271).

O dialogismo, para Bakhtin/Volochínov (2014), constitui as práticas nas quais estão inseridas as atitudes responsivas dos interlocutores, nas quais os sujeitos se revelam como seres constituídos sócio-historicamente. "O diálogo - o intercâmbio verbal - representa a forma mais natural da linguagem." (VOLOSHINOV, 2013a, p. 163). Sendo assim, a palavra, como elemento dialógico, se apresenta preenchida de determinados valores sociais; ela é toda interação viva dos sujeitos nas esferas sociais.

\section{Análise dialógica do discurso: da teoria à confrontação dos fatos}

\section{Descrição da constituição do enunicado 1}

O enunciado $1^{4}$ é composto pelas imagens de três mulheres vestidas com roupas executivas (paletó e gravata). Essas mulheres estão postas na seguinte ordem: $(A)$ a que está no meio das duas outras está com os braços cruzados, olhando, de frente, na direção do leitor; além disso, o seu rosto expressa tons de um possível sorriso (um sorriso bem tímido); (B) na posição do olhar do leitor, a que está do lado esquerdo da do meio, é loira, usa óculos e está fazendo um gesto (com as mãos) de uma arma apontada para cima e um gesto, com o boca, de quem está soprando o cano da arma, bem como está um pouco de lado, olhando em direção ao leitor; (C) na posição do leitor, a que está no lado direito está olhando, de frente, para o leitor, usa óculos e, com a mão esquerda, pega de leve no canto dos óculos, fazendo pose de intelectual. Por trás dessas mulheres, como pano de fundo, existe uma imagem vermelha e branca representando a marca Bombril. $\mathrm{Na}$ frente das mulheres existe um balcão, brilhando de tão limpo e, em cima deste, existe uma fila (horizontal) de diversos produtos da marca mencionada.

No enunciado 1 os sentidos que são construídos, sob a imagem da mulher, estão relacionados à historicidade da mulher como um sujeito deslocado de uma função social cristalizada pelo tempo (a mulher doméstica). Ao mesmo tempo, esse deslocamento constrói a figura feminina como um ser social, constituído de

\footnotetext{
4 A imagem 1 é encontrada no blog Macho das cavernas, no segunte endereço:
} http://machodascavernas.blog.com/2011/04/18/propaganda-feminista-da-bombril-sera 
elementos axiológicos estabelecidos pelas forças sociais que atribuem a esse sujeito uma função de executiva (a mulher moderna).

Esses fios de sentido, no presente enunciado, podem ser percebidos através da figura da mulher executiva em contraste com os diversos produtos de limpeza. Sendo assim, a mulher executiva é discursivizada com tons de seriedade, poder, bem como pelas vozes sociais que enunciam o discurso da prosperidade, da conquista e do sucesso.

Dentre os elementos histórico-axiológicos que estabelecem sentidos à construção da imagem feminina, ainda podemos destacar a figura da mulher construída pelos gestos imagéticos da mulher valente (com uma arma na mão). Esse elemento pode ser harmonizado com os fios de sentido estabelecidos pelos tons de inteligência, beleza e elegância. Essa conjuntura serve de elemento fundamental para o acabamento do enunciado imagético, ou seja, para estabelecer, na imagem feminina, os sentidos que constituem a mulher moderna em detrimento à imagem da mulher doméstica.

Outro fator que deve ser destacado é o horizonte espacial, o lugar no qual a mulher está situada (a mulher atrás do balcão). Nesse caso, mesmo havendo vários produtos de limpeza em cima do balcão e, mesmo que o balcão apresente características de limpeza, refletindo brilho e espelhando o reflexo dos produtos, pelo lugar ideológico onde a mulher está situada, não se estabelece a função social da mulher como a doméstica.

O horizonte ideológico estabelece, para a mulher, uma função social de relevante prestígio e isso pode ser visto no enunciado devido à relação entre os possíveis sentidos da mulher doméstica que podia estar limpando o balcão e a mulher executiva, a empresária que está vendendo o produto de limpeza e se constitui como um sujeito social caracterizado na esfera ideológica da economia.

A relação de oposição entre a mulher doméstica e a mulher executiva estabelece sentidos que são construídos pela historicidade da figura feminina constituída por traços dialógicos entre os sentidos da historicidade da dona de casa e da mulher de negócios. Essa dialogicidade se constitui pela luta social compreendida como um elemento axiológico caracterizante da mobilidade de sentidos, construída pelas vozes sociais que instauram o sujeito mulher como um ser social em devir. 
Ao observar o enunciado 1 , constatamos signos constituídos pela materialidade semiótica de vestes relacionadas à esfera executiva (o terno e a gravata, costumeiramente usados por homens). Essa constituição sígnica configura à figura feminina tons de segurança, respeito e habilidade na arte de anunciar o produto, bem como na venda e na utilização dos produtos de limpeza (Bombril). No entanto, o enunciado 1 apresenta um valor ideológico que constitui a mulher como um sujeito que já fez o trabalho de uma boa dona de casa com a utilização do produto de limpeza da marca (Bombril), mas também como um sujeito inserido na esfera do domínio executivo.

No que diz respeito aos gestos de seriedade, de superioridade e de poder da mulher (com a arma na mão), podemos destacar que essa comunhão de tons axiológicos atribui segurança ao produto, representando a ideia de ser uma arma poderosa a ser usada na limpeza. Outro aspecto de extrema importância no enunciado 1 é a ideia de que a enunciação dos produtos da Bombril têm sentidos históricos relacionados aos deslocamentos de sentidos na historicidade da figura feminina. Isso demarca a mobilidade de sentidos que se estende desde a figura da mulher como doméstica que usava o produto à figura da mulher que realiza a venda do produto.

A história da inserção da mulher no mercado de trabalho é instaurada pelas vozes presentes em diversos momentos sociais que estabelecem o poder da figura feminina relacionada às conquistas financeiras na vida fora do lar. Os valores que são atribuídos à mulher como um sujeito do lar são elementos de orientação opositiva que configura a ideia de um sujeito social que surge a partir de uma relação de mobilização de gênero e de luta de classe.

Podemos afirmar que a carga valorativa social e axiológica existente na situação do enunciado 1 configura a materialização da imagem feminina como um elemento sociocultural de extremo valor para a enunciação publicitária de produtos de limpeza. Assim, os sentidos do enunciado 1 refletem a discursivização do sujeito mulher doméstica e seu possível deslocamento na construção do sujeito mulher executiva. 


\section{Descrição da constituição do enunicado 2}

O enunciado $2^{5}$ é composto pelos desenhos das silhuetas de duas pessoas (um homem e uma mulher). Essas imagens têm tamanhos iguais, estão de frente para o leitor, e tanto o homem quanto a mulher das imagens estão, respectivamente, com uma das mãos levantadas e com a outra segurando um cartaz com o seguinte enunciado: homens mandam e mulheres mandam.

No enunciado 2, o dizer é constituído pela harmonização das vozes sociais que enunciam sobre a ideologia dos conflitos existentes entre representantes do sexo masculino e feminino. Nesse enunciado, podemos compreender a ideia de que os sujeitos do discurso estão travando uma luta entre ideologias sexistas. Entretanto, como característica de uma sociedade machista, a igualdade pode ser compreendida como uma exigência de direito de igualdade da mulher.

Por outro lado, pode ser compreendido, também, pelos tamanhos iguais das duas imagens (do homem e da mulher), que esse conflito pode partir da representação masculina. De fato, as imagens expressam sentidos de lutas de igualdade entre homens e mulheres. De maneira mais específica, esse conflito pode demonstrar uma forma de protesto, já que a mulher, aos poucos, vem conseguindo o seu espaço na sociedade, e os homens talvez se sintam ameaçados com o poder da representação feminina.

As vozes sociais, no enunciado 2 , expressam sentidos que estabelecem uma distinção entre as classes de gêneros. Assim, podemos destacar horizontes temporais e espaciais que configuram elementos axiológicos que foram constituídos pela força da historicidade que construiu a figura da mulher como um sexo frágil que vivia sobre a proteção do homem. Se, no passado, a mulher era compreendida como submissa ao homem (em todas as formas), a imagem feminina era construída sob a forma de esposa, de dona de casa que vivia para cuidar dos filhos. Essas ideias caracterizaram a mulher como um sujeito que tem como função social a proteção do lar. No caso dos homens, podem ser compreendidos como sujeitos com

\footnotetext{
5 A imagem 2 é encontrada no blog da Lígua Teixeira, no seguinte endereço: http://blog. jornalpequeno.com.br/ligiateixeira/2015/02/02/nao-sou-feminista-e-machismo-nao-e-privilegio-dehomens-robert-lobato/
} 
função social de maridos a trabalhadores, que passam boa parte do tempo fora de casa.

No enunciado 2, podem ser estabelecidos sentidos de que a mulher deixou, há muito tempo, de ser um sujeito social com função de se dedicar apenas aos afazeres domésticos e foi em busca de igualdade de gênero. Isso demonstra um conflito entre valores e vozes sociais que estabelecem o sujeito mulher como um ser social construído pelos valores axiológicos de uma sociedade constituída por sujeitos de direitos e garantias fundamentais instituídos pelas forças normalizadoras do Estado Democrático de Direito.

\section{Descrição da constituição do enunicado 3}

O enunciado $3^{6}$ é composto pelos seguintes enunciados: (A) lugar de mulher é .; (B) seja como for que esta frase termine, ela está errada.

No enunciado 3, são estabelecidos sentidos que demarcam o conflito relacionado ao lugar social do sujeito mulher.

A expressão "Lugar de mulher é" configura sentidos diversos. Dentre eles, pode ser formulada a ideia de que existem muitos lugares sociais que podem ser ocupados pela mulher e não apenas os lugares relacionados às atividades do lar. Essa expressão parte da enunciação subentendida de vozes sociais relacionadas ao preconceito machista de que a mulher não pode ocupar certas funções sociais tradicionalmente destinadas aos homens.

O espaço a ser preenchido pelo enunciado formado pela linha e pelo ponto (_.) pode ser compreendido como a construção de múltiplos enunciados subentendidos, pois, quando se abre espaço para possíveis complementos do enunciado Lugar de mulher é, podemos destacar que o enunciado 3 discursivizada a construção de possíveis enunciações relacionadas à função social da mulher na sociedade (pós)moderna.

Por outro lado, na expressão "seja como for que esta frase termine, ela está errada", podemos compreender que podem ser subentendidos sentidos que

\footnotetext{
${ }^{6}$ A imagem 3 é encontrada no site Cintiacosta.com, no seguinte endereço: http://cintiacosta.com/2013 /03/05/as-propagandas-de-produtos-de-limpeza-e-o-machismo/
} 
estabelecem tanto a opinião machista de que a mulher não pode ocupar funções e espaços ideológicos que não sejam relacionados ao lar, como também a opinião jurídico-constitucional relacionada à concessão de direitos e garantias fundamentais que configuram a ideia de que todos os indivíduos, independentemente de serem sujeitos sociais do sexo masculino ou feminino, devem ser compreendidos e tratados com igualdade social.

O deslocamento de posições e funções sociais ocupados pela mulher na sociedade contemporânea rompe com a formação ideológica da figura da mulher como dona do lar. Os sentidos ideológicos que se faziam presentes na esfera social familiar, com a figura da mulher doméstica, foram descolados para um sentido que estabelece a mulher como um sujeito social constituído pelas forças axiológicas de uma sociedade igualitária.

Assim, podemos compreender que as lutas feministas em busca das suas ideologias de igualdade visam à ideia de igualdade entre as classes de gêneros, não apenas na questão da composição ontológica do gênero, mas nas possibilidades de igualdade dos papéis sociais assumidos pelas mulheres.

Através do enunciado 3, podemos compreender que os sentidos axiológicos relacionados à igualdade de gênero estabelecem uma luta de classes e um estilo de vida no qual toda mulher possa viver de maneira digna sem sofrer preconceitos machistas.

\section{Descrição da constituição do enunicado 4}

No fundo do Enunciado $4^{7}$ existe uma folha de papel ofício inclinada um pouco para a esquera (a partir da posição do leitor). Nessa folha, existe um desenho de uma menina (da cintura para cima) com uma blusa vermelha bem curta e com o cabelo solto com uma parte cobrindo o olho direito. Acima da cabeça da menina existe o enunciado: não me dou o respeito (porque ele é meu por direito).

No enunciado 4, a figura feminina está sendo discursivizada como uma mulher quase despida, com os braços e a barriga à mostra, uma blusa bastante decotada e cabelo encaracolado. Pela imagem podem ser estabelecidos sentidos

\footnotetext{
7 A imagem 4 é encontrada na página Feministas Revolucionárias do Facebook, no seguinte endereço: https://www.facebook.com/FeministaRevolucionaria/photos/a.1426924547573178.107374 1829.1426897154242584/1553006351631663/?type=3\&theater
} 
relacionados a uma mulher não submissa, que defende os seus direitos e as suas ideologias, uma mulher desprendida da opinião e da avaliação de julgamento social.

$\mathrm{Na}$ expressão "Não me dou o respeito (Porque ele é meu por Direito)", a discursivização da mulher constrói possibilidades de sentidos nos quais o sujeito mulher se insere nos envoltos dos discursos constitucionais e toma consciência de um fato jurídico-social (sujeito de direito natural) que desconstrói a ideia de exclusão ou de luta por algo já garantido. Desse modo, podem ser estabelecidos sentidos relacionados à consciência de que existem dispositivos legais que garantem o direito de se constituir como um sujeito em devir e livre de quaisquer preconceitos ou de juízos de valores sociais.

O sujeito mulher toma consciência do direito de ser livre e de ser respeitada pelas valorações constituídas da sua constituição subjetiva. A expressão não me dou o respeito possibilita um fio de sentido caracterizado pelo apelo à compreensão avaliativa e a atitude responsiva do outro. Desse modo, a conscientização do direito natural se institui como uma resposta aos discursos de rejeição e de preconceito que existem sob a figura da mulher como um sujeito marginalizado. Portanto, o enunciado 4 estabelece sentidos relacionados à imagem da mulher como um sujeito livre de julgamentos sociais, bem como a discursivização da imagem feminina como um ser consciente e constituído de direito.

\section{Considerações finais}

A discursivização das imagens femininas estabelece sentidos com uma elevada carga valorativa, principalmente no que diz respeito à historicidade e à axiologia constitutiva dos enunciados imagéticos. A imagem feminina nem sempre é discursivizada como um sujeito frágil e submisso ao ser observado o seu horizonte temporal (contemporâneo); notamos que são constituídos pontos de vista deslizantes no que concerne a mobilização histórica da compreensão coletiva do sujeito mulher como um ser social em devir.

Pudemos constatar, ao analisar os enunciados, que a enunciação da imagem feminina apresenta rupturas na construção de sentidos estabelecidos pela sociedade contemporânea. Assim, à figura feminina são atribuídos sentidos referentes ao processo de lutas sociais e de conscientização, que, de maneira 
particular, preconiza o sujeito mulher como uma construção social permeada pelos sentidos de igualdade em relação à classe masculina.

A decorrência do elemento histórico-temporal referente à contemporaneidade institui que as vozes jurídico-constitucionais são fatores preponderantes para a discursivização do sujeito mulher como um sujeito de direito igualitário. Sendo assim, os elementos histórico-axiológico-constitucionais instauram a força motriz para que hajam condições discursivas no processo de enunciação do ser-mulher como uma construção flutuante de sentidos, ou seja, como um sujeito enunciado pela ordem social que promove a igualdade entre os seres sociais.

As relações de sentido na imagem feminina demarcam o lugar social da mulher como um sujeito constituído de traços refratários. Desse modo, a imagem feminina é construída pelas diversas discursivizações das lutas sociais referentes à igualdade entre os gêneros masculinos e femininos.

Para efeito de fim, afirmamos que foram respondidas as perguntas exploratórias e a problemática da pesquisa. Assim, podemos destacar que: (1) a relação de sentidos no deslocamento da imagem feminina dispersada pelo tempo mostra que o sujeito mulher foi discursivizado a partir da enunciação de diversas vozes sociais que constituem os elementos histórico-axiológicos pertinentes à construção de um sujeito formado no processo das lutas de classe e de gênero; (2) a construção da enunciação de um sujeito igualitário de direito se fez pela enunciação de vozes jurídico-constitucionais, principalmente aquelas subentendidas no artigo $5^{\circ}$ da Constituição Federal, que estabelecem o direito de igualdade aos indivíduos; (3) os sentidos estabelecidos na discursivização da imagem feminina nas redes sociais se constituíram pelo cruzamento das vozes jurídico-constitucionais e pelas vozes axiológicas referentes ao processo de conscientização social (lutas sociais de classe e gênero) de que a mulher não é um ser inferior ao homem apenas pelo fato de ser mulher.

Ao analisar a imagem feminina pela ótica dos estudos do Círculo bakhtiniano, compreendemos que os sentidos que constituem o sujeito mulher de direito igualitário são estabelecidos por meio da inserção desse sujeito no contexto social, histórico e ideológico. Assim, a construção subjetiva que atribui valores sociais à imagem feminina se faz pelo cruzamento dos discursos realizados no passado, pela atualidade dos discursos que circulam no presente, bem como pela atitude 
$\mathbb{B}_{\text {dissei }} \mathcal{A}$

ISSN: 1983 2435)

responsiva (tardia) dos discursos futuros como atos responsivos tanto dos discursos passados como dos discursos presentes.

\section{Referências}

BAKHTIN, Mikhail. Os gêneros do discurso. In: Estética da criação verbal. Prefácio à edição francesa por Tzvetan Todorov; introdução e tradução do russo de Paulo Bezerra. 6. ed. São Paulo: Martins Fontes, 2011, p. 261-306. (Coleção Ensino Superior).

BAKHTIN, Mikhail/VOLOCHÍNOV, V. N. Marxismo e filosofia da linguagem: problemas fundamentais do método sociológico na ciência da linguagem. Trad. Michel Lahud e Yara F. Vieira. 16. ed. São Paulo: Hucitec, 2014.

COSTA, Cíntia. As propagandas de produtos de limpeza e o machismo. Disponível em: <http://cintiacosta.com/2013/03/05/as-propagandas-de-produtos-de-limpeza-e-omachismo>. Acesso em: 21 mar. 2015.

FACEBOOK. Feministas Revolucionárias. Disponível em: <https://www.facebook. com/FeministaRevolucionaria/photos/a.1426924547573178.1073741829.14268971 54242584/1553006351631663/?type=3\&theater>. Acesso em: 21 mar. 2015.

MACHO DAS CAVERNAS. Propaganda Feminista da BomBril. será? Disponível em: $<$ http://machodascavernas.blog.com/2011/04/18/propaganda-feminista-da-bombrilsera/>. Acesso em: 21 mar. 2015.

COSTA, Marcos Antonio. Estruturalismo. In: MARTELLOTA, Mário Eduardo (Org.) Manual de línguistica. São Paulo: Contexto, 2010, p. 113-126.

OLIVEIRA, Antonio Flávio Ferreira de. A entoação avaliativa na defesa criminal no tribunal do júri: contribuições da teoria dialógica da linguagem. 2015. $114 \mathrm{f}$. Dissertação (Mestrado em Linguística) - Universidade Federal da Paraíba, João Pessoa, 2015.

SAUSSURE, Ferdinand de. Curso de línguistica geral. Organizado por Charles Bally e Albert Sechehaye ; com a colaboração de Albert Riedlinger; traduzido por Antônio Chelini, José Paulo Paes e Izidoro Blikstein. 28. ed. São Paulo: Cultrix, 2012.

VOLOCHÍNOV, Valentin N. A construção da enunciação. In: GERALDI, João Wanderley (Org.). A construção da enunciação e outros ensaios. Tradução e notas de Joao Wanderley Geraldi. São Carlos, SP: Pedro \& João Editores, 2013a, p. 157188.

VOLOCHÍNOV, Valentin N. Palavra na vida e palavra na poesia. Introdução ao problema da poética sociológica. In: GERALDI, João Wanderley (Org.). A construção da enunciação e outros ensaios. Tradução e notas de Joao Wanderley Geraldi. São Carlos, SP: Pedro \& João Editores, 2013b, p. 71-100. 
$\mathbb{B}_{\text {dissei }} \mathcal{A}$

TEIXEIRA, Lígia. Blog da Lígia Teixeira. Disponível em: <http://blog. jornalpequeno.com.br/ligiateixeira/2015/02/02/nao-sou-feminista-e-machismo-nao-eprivilegio-de-homens-robert-lobato/ >. Acesso em: 21 mar. 2015.

Recebido em 15/06/2016

Aprovado em 25/06/2016 